\title{
TheGMS
}

\section{Current trends in identifying biomarkers in endometrial cancer}

\author{
Dr Brinderjeet Kaur ${ }^{1 *}$ \\ ${ }^{1}$ Consultant Department of Obstetrics and Gynecology, Santokba Durlabhji Memorial Hospital and Research Center, Jaipur, India. \\ Address for correspondence: \\ Dr Brinderjeet Kaur, Consultant Department of Obstetrics and Gynecology, Santokba Durlabhji Memorial Hospital and Research Center, Jaipur, India. \\ Email: dr.bjkaur@gmail.com \\ Submitted: 08 May 2020 \\ Approved: 14 May 2020 \\ Published: 18 May 2020 \\ How to cite this article: Kaur B. Current trends in identifying biomarkers in endometrial cancer. G Med Sci. 2020; 1(1): $047-054$. \\ https://www.doi.org/10.46766/thegms.gyn.20050802 \\ Copyright: @ 2020 Brinderjeet Kaur. This is an open access article distributed under the Creative Commons Attribution License, which permits unre- \\ stricted use, distribution, and reproduction in any medium, provided the original work is properly cited.
}

\section{ABSTRACT}

Endometrial cancer (EC) is the sixth most common cancer in women and accounts for about $8.2 \%$ of the worldwide incidence of cancer in women. Its incidence varies across regions and is rising as life expectancy increases. Although, there have been significant recent advances in our understanding of endometrial cancer. But there is paucity of a reliable screening test. When diagnosed at an early stage, EC is highly curable and has excellent overall 5 -year survival rates. Delayed diagnosis contributes to advanced stage at the time of presentation and therefore poor survival. Early diagnosis is key to improving survival. As of now, there are no validated biological makers for its early detection. The present article attempts to analyze the approaches which may contribute to find relevant biomarkers to be used as screening, diagnostic and prognostic value to patient with endometrial cancer.

\section{Introduction}

Endometrial cancer (EC) is the sixth most common cancer in women and accounts for about $8.2 \%$ of the worldwide incidence of cancer in women. Its incidence varies across regions and is rising as life expectancy increases $(1,2)$. When diagnosed at an early stage, EC is highly curable and has excellent overall 5 -year survival rates (3). Delayed diagnosis contributes to advanced stage at presentation and poor survival.

Post menopausal women with vaginal bleeding undergo various tests to exclude EC, including transvaginal ultrasound scan (TVS), Outpatient hysteroscopy (OPH) and endometrial biopsy (EB) (4). While these procedures are expensive and difficult to perform, their diagnostic utility for EC is limited by poor specificity (TVS) and unacceptable levels of invasiveness and discomfort (OPH, EB) $(3,4)$. The measurement of endometrial thickness (ET) with TVS for instance, although minimally invasive and highly sensitive for EC detection ,is plagued by a markedly low specificity as multiple benign pathologies especially polyps, intracavitary fibroids or blood clot, artifacts create the appearance of a thickened endometrium . $(3,4)$ Endometrial biopsy, the gold standard for diagnostic evaluation of women with suspected EC , can sometimes miss focal pathologies, especially when done blindly using office based sampling devices such as pipette. The procedure is not only painful in nulliparous women but has high risk of insertion failure (3, 5). Hysteroscopy with directed biopsy, on the other hand, has better diagnostic sensitivity but is expensive, has high failure rate in outpatient clinic and over $30 \%$ women experience severe pain or vasovagal episode during its completion. There is theoretical risk of disseminating cancer cells into the peritoneum, rarely life-threatening complications 
ensue, e.g. uterine perforation $(3,6)$.

The ideal EC detection tool should be simple, non invasive, have ability to reliably detect all EC at the earliest stage with few false positives and negatives. Such a tool may be used to screen high risk asymptomatic women, or those with Lynch syndrome, who have a high lifetime risk of developing EC. Early detection could enable conservative management options to young women desirous to complete childbearing and morbidity obese women in whom surgery is potentially hazardous (4). Diagnostic biomarkers that identify specific subtypes of EC, for example POLE, Ultramutated EC, would also provide prognostic and predictive information and could be used to monitor response to therapy and detect recurrent disease.

EC have traditionally been classified into two histological categories Type 1 and type 2 (Bokhmans dualistic model). (7) Type I tumors make up 80-90\% of endometrial cancers and are estrogen responsive, have a favorable prognosis, and may be preceded by a precancerous condition (atypical hyperplasia). Type II tumors, account for only 10-20\% of endometrial cancers and are usually estrogen independent, high grade and clinically aggressive. $(7,8)$

\section{Newer classification}

A recent and pragmatic classification of EC based on a multiplatform (genomic and transcriptomic) analysis categories EC into 4 distinct molecular subtypes of prognostic relevance: $[9,10]$

- $\quad$ Polymerase epsilon (POLE)- Unmutated

- $\quad$ Microsatellite instability (MSI)- Hypermutated

- $\quad$ Copy number low - Microsatellite stable (MS)

- $\quad$ Copy number high - Serous type

\section{Search for EC diagnostic markers}

Human genome was decoded in 2001 and it opened avenues for information on complete human genome thereby enabling the discovery of biomarkers and new diagnostic tests [12-17]. The high throughput technologies like genomic, transcriptomic, proteomic, metabolomic and imaging analysis have enormous potential as large-scale biomarker discovery (14).

Nair et al [13] cfDNA fractions of uterine lavage samples and Lim et al [14] using the cervical swab samples [14], both using Next generation sequencing for biomarker detection in EC patients however found limited application due to high false positive rates. It also became evident that development of EC is solely not based on genomics only rather environmental factors play major role in disease causation [12]. There is lot of information at cellular, subcellular and intracellular levels that is not explained by genomics alone [15]. This led to integration of epigenomic transcriptomic, proteonomic and metabolomic data incorporation. The biomarker search at epigenetic based platforms had limitations as they were non quantitative or semi quantitative with poorly defined cut offs based on test and control genes and hence poor reproducibility in routine clinical setting [14].

The application of high throughput technology in study of RNA is known as transcriptomics. It allows the characterization of genetic expression at $\mathrm{m}$ RNA level [15]. However, EC transcriptome in cancer genome could not provide information on differential expression in EC verses non-EC endometrial tissue [16]. It is still expected that as transcriptomics reflect dynamic cell state, they have great potential to yield useful biomarkers [17].

\section{Proteomics}

Nowadays protein identification with altered expression in cancers is done by employing advanced techniques like two-dimensional gel electrophoresis and mass spectrometry-based analysis [18]. Whereas 2D gel electrophoresis has low throughput [19] others like Enzyme linked immunosorbent assay (ELISA) and Immunohistochemistry (IHC) could easily be employed in resource limited settings as well [20].

The choice of biological specimens' chosen for protenomic analysis is dictated by ease of availability and invasiveness of procedure to obtain sample. Hysterectomy, endometrial biopsy specimens and uterine lavage samples are viable source of cancer derived proteins but their retrieval is not easy. Blood is most accessible and minimally invasive fluid for examination but its use is limited by low quantity of tumor related signals in circulation in early stage of disease process [21, 22]. 
An effective sample preparation is essential for successful biomarker discovery [23]. Tissue based proteomic studies could be done by using laser capture micro dissection (LCM) but there is no standard technique for sample preparation from blood and it depletes high abundant proteins [17]. Although the acceptability of blood (serum/ plasma) as potential source of biomarkers for EC is high but the real challenges comes from the matrix and therefore have poor concordance with time derived proteins.

\section{Blood as source of biomarkers}

Peripheral blood has circulating tumor cells (CTC), circulating tumor DNA (ct DNA), proteins and extracellular vesicles all having potential to serve as biomarkers. Table-1 shows the various blood-based biomarkers that are under research. Unfortunately, currently there is insufficient data to support any of the blood-based biomarkers for EC diagnosis. There have been inconsistent study findings, poor accuracy and lack of validation of blood-based markers rather they have been used for prognostification. The most promising blood base markers include HE4 (WFDC2) and CA 125 (MUC 16) which are also found in tissue based EC samples and have been validated in literature studies [25,26] .The sensitivity and specificity of HE4 in EC specimen was 0.65 and 0.9 in study by Li and colleagues [26]. The results using CA 125 are unsatisfactory [25]. To improve diagnostic accuracy of HE4 and CA125 some researchers have suggested to add body mass index (BMI) \{ Knifie et al [27]\} and Prolactin \{Yurkovetsky [28]\}. Prolactin has been found to increase in ovarian, lung and pancreatic carcinoma limiting its utility as EC marker [28].

\section{Table - 1 Blood markers for EC}

\begin{tabular}{lll}
\hline Marker & Promising & \\
Prolactin & Technique & Nature \\
Human Epididymis Protein 4(HE4) & Bead based immunoassay & Secretion by stromal cells \\
CA125, CA72.4, CA 15.3 & Enzyme immunoassay & Whey acidic protein family \\
Human chitinase 3 like protein 1(YKL-40) & ELISA & Mucin family glycoprotein \\
Adiponectin & ELISA & $\begin{array}{l}\text { Glycoprotein chitinase } \\
\text { family }\end{array}$ \\
& ELISA & $\begin{array}{l}\text { Adipokine metabolic, im- } \\
\text { mune function }\end{array}$
\end{tabular}

\section{Cyclophilin A}

Sperm associated antigen

Growth related oncogen ALPHA (cxcl1)

Growth differentiation factor 15 (GDF - 15)

FAS

Leucine rich glycoprotein (LRG1)

Transthyretin

inter alpha trypsin inhibitor family heavy chain

related peptide

Cleavage high molecular kininogen

ICAM

Interleukin 31,33, 2R

\section{Limited use biomarkers}

TNF Receptor 1A

Colony stimulating factor CSF1

Alpha fetoprotein

Alpha beta glycoprotein

Complement (C3, C4, C4B)

Clustering (CLU)

Antithrombin III

Alpha 1 antitrypsin

Visfalin (NAMPT)

TSH, ACTH, FSH

\section{Inconsistent}

biomarkers

Matrix metalloprotein MMP 2,7,9

Serum Amyloid A (SAA)

apolipoproteins (A-IV0 C1

Dickkopf related protein 3 precursor

VEGF 


\section{Proteomic analysis of tissue samples}

The tissue biomarkers have been broadly categorized as - chaperones / heat shock proteins ( HSP 10, 27, 70, 71) , enzymes ( pyruvate kinase ( PK) , phosphoglycerate kinase (PGK -1) , phosphoglycerate mutase 2 (PGAM 2 ), alpha enolase (ENO -1) , enzyme inhibitors ( alpha -1- antitrypsin precursors (SERPINA 1 ) , calcium binding proteins calgranulin ( S- 100A8/9) , calgizzarin (S-100A11) , calyphosine (CAPS ), fatty acid binding protein ( epidermal fatty acid protein ( FABP5) and calyphosine protein among others. Molecular chaperons are implicated in tumor cell proliferations and differentiation but their non specificity is a major hurdle [29, 30, and 31. In combination with other proteins, however they are likely to be strong candidate for EC detection and warrant further exploration.

Expression of p53 protein and / or p53 gene mutations have been detected in 7-43\% of EC and have been associated with advanced stage, high grade, deep myometrial invasion, type 2 histology, lymph node metastasis and ultimately , lower survival compared with EC patients without p53 alterations (31-37) PTEN mutations are related to early stage, low rate of p53 over expression and longer survival in women with EC .(38) Loss of PTEN function does appear to impact on survival of patients with early disease, but it was associated with a better clinical outcome in those with advanced or recurrent disease . (39)

MSI (Microsatellite instability) which is the hallmark of defects in DNA mismatch repair genes occurs in 11-45 \% of type $1 \mathrm{EC}(39,40$, and 41). Whereas MSI is an independent predictor of a favorable outcome in colorectal cancer (42), conflicting data emerge from the literature as far as the prognostic relevance of MSI in the Type $1 \mathrm{EC}$ is concerned.

Alterations in Beta catenin expression has been reported both in type $1 \mathrm{EC}$ and atypical hyperplasia and therefore appears to represent an early event in endometrial carcinogenesis. Saegusa et al assessed 199 cases of type $1 \mathrm{EC}$, found a significant association between beta catenin mutations and low grade histological malignancy $(p=0.048)$, as well as between beta catenin mutations and lack of lymph node involvement . (43)

$\mathrm{K}$ - ras mutations which are most commonly seen in type $1 \mathrm{EC}$ has been associated with lymph node metastasis and poor survival. $(43,44,45)$ For example, Mizuuchi et al investigated 49 cases and concluded that the presence of K-ras mutations was an independent predictor of unfavorable clinical outcome $(\mathrm{p}=0.034)$ after adjusting for tumor stage, depth of myometrial invasion and patient age

Vascular endothelial growth factor (VEGF)is an important endothelial cell mitogen that acts through specific receptors, namely flt-1 and flk -1/KDR (46). In EC, an increase in VEGF expression has been associated with advanced tumor stage, high tumor grade, deep myometrial invasion, lymphovascular space involvement and lymph node metastases. $(47,48,49)$

The proportion of aneuploid tumors among EC ranges from 16 to $28 \%$ and significantly correlates with old age at diagnosis, type 2 histology, high tumor grade and lymph node involvement. In most studies patients with aneuploid tumors have significantly poorer survival at multivariate analysis, after adjusting for the common clinical -pathological variables $(51,52,53)$. In fact, some authors have suggested including DNA ploidy among criteria for the selection of high-risk patients who might benefit from adjuvant treatment.

Hormone receptor status has consistently been shown to be a relevant prognostic marker that could also influence the choice of treatment for metastatic disease, due to higher response rates reported for hormone receptor positive tumors. The presence of steroid receptors correlates with low grade, type 2 histology as well as favorable outcome in many studies $(21,27)$. Hormone receptor status in curettage and hysterectomy specimens has been reported to be highly correlated with favorable prognosis and with good to very good reproducibility for pathological staining assessment. On the contrary, loss of estrogen and progesterone receptors in curettage specimens has been significantly associated with aggressive phenotypes and poor survival in patients with EC (27). Table-2 shows the various tissuebased biomarkers that are under research. 
Table 2 Tissue based biomarkers for EC

Chaperonin 10 9CPN)

\section{Consistent}

Piruvate Kinas (PK)

\section{Limited evidence}

Cyclophilin A

Caligizzarin

Epidermal fatty acid binding protein

Calgrunulin A

HSP 27, HSP 47

Proinhibin

Transgelin

Phosphoglycerate kinase

Creatinekinas B

Glutathione synthetase

Serotransferrin receptor
Alpha enolase

Superoxide dismutase

Fibrinogen beta chain

Anterio gradient protein

Macrophage migratory inhibitor

Alpha 1 antitrypsin

Protein deglycase

Annexin 1-2

Peroxidases 1-4

Costar family

Desmin

\section{Urine sample}

Urine is cheap, easily accessible, easy to collect and in study by Mu et al [54] found up regulation of Zinc alpha 2 glycoprotein, alpha 1 acid glycoprotein and CD 59 in EC patients compared to normal healthy subjects. The urine-based biomarkers rely on renal excretion of these markers or urinary contamination by uterine biomarkers. This poses major problems and makes them unreliable as many of them occur in urine as uterine shedding biomarker rather than true urinary excreted ones [55].

\section{Ideal biomarker}

The majorities of biomarkers are at discovery phase and fail to pass validation studies. Subject selection bias [56] is a problem with validation of these markers. Racial differences, age related normal control (healthy) subjects and postmenopausal woman selection create discriminatory results and skewed findings. A small sized study leads to erroneous conclusions. Many a times spurious signals [57] are introduced as a result of specimen collection at different time points, storage conditions, all these mandate standard operating procedures for all steps involving sample collection, processing and interpretation.

\section{Conclusion}

Biomarkers have the potential to help screening, diagnosing and staging the disease and could complement conventional means. At the moment, biomarkers utilization and research are more relevant in facilitating staging of EC and thus guiding treatment and aiding prognosis. Biomarker utilization in screening and diagnosis is much less developed. There are important limitations that need to be overcome in the future to allow adequate implementation of new biomarkers to guide clinical care in EC. 


\section{Recommendations}

Therefore, further new studies should be undertaken so that we are able to work out the best possible biomarker for EC. The following parameters may be included for a better outcome

- $\quad$ Sufficiently sized, population

- $\quad$ Test criteria applied for new surgical staging procedures with lymphadectomy should be better standardized

- $\quad$ Reproducibility

- $\quad$ Practical application in routine clinical settings

\section{References}

1. Bray F, Ferlay J, Soerjomataram I, Siegel RL, Torre, L.A, Jemal A. Global cancer statistics 2018 GLOBCAN estimates of incidence and mortality worldwide for 36 cancers in 185 countrues . CA Cancer J. Clin. 2018, 68, 394-424 [CrossRef][PubMed ]

2. Lortet - Tieulent, J; Ferlay J ; Bray , F ; Jemal , A. International patterns and trends in endometrial cancer incidence , 1978-2013 . J Natl . Cancer Inst . 2018, 110 , 35-361.[ CrossRef] [ PubMed ]

3. Sundar, S; Balega J;Crosbie, E; Drake , A; Edmondson, R;Fotopoulou, C; Gallos , I; Ganesan ,R; Gupta J; Johnson, N. BGCS uterine cancer guidelines ; Recommendations for practice . Eur j. Obstet . Gynecol. Reprod Biol 2017, 213,71-97 . [ CrossRef] [ PubMed ]

4. Colombo, N; Creutzberg ,C;Amant ,F;Bosse, T ;Gonzalez -Martin ,A ;Ledermann ,J; Marth , C; Nout, R; Querleu, D ; Mirza , M.R;et al. ESMO-ESGO-ESTRO Consensus Conference on Endometrial Cancer Diagnosis , Treatment and Follow -up .Int.J.Gynecol Cancer 2016, 26,2-30 .[ CrossRef ] [ PubMed ]

5. Guido, R; Kanbour -Shakir ,A;Rulin ,M;Christopherson ,W. Pipelle endometrial sampling .Sensitivity in the detection of endometrial cancer .J.Reprod.Med.1995, 40,553-555 .[ CrossRef] [ PubMed ]

6. Clark, TJ;Voit ,D;Gupta, JK;Hyde ,C;Song,F; Khan ,KS.Accuracy of hysteroscopy in the diagnosis of endometrial cancer and hyperplasia : A systematic quantitative review [AMA 2002,288,1610-1621. ] .[ CrossRef] [ PubMed ]

7. Bokhman , J.V .Two pathogenetic types of endometrial carcinoma . Gynecol. Oncol 1983,15, 10-17 .[ CrossRef ]

8. Suarez ,A.A;Felix , A.S; Cohn , D. E. Bokhman redux: Endometrial cancer “types" in the $21^{\text {st }}$ century Gynecol. Oncol. 2017, 144,243-249.[ CrossRef ]

9. Talhouk , A; McConechy , M.K; Leung , S; Yang, W; Lum ,A;Senz J;Boyd, N; Pike , J; Anglesio ,M;Kwon , JS. Confirmation of ProMisE : A simple, genomics based clinical classifer for endometrial cancer . Cancer 2017, 123, 802-813 . [ CrossRef]

10. Stelloo ,E; Bosse ,T;Nout, R.A; MacKay , H.J;Church, D.N; Nijman, H.W; Leary , a;Edmondson , R.J; Power,M.E;Crosbie ,E.J. Refining prognosis and identifying targetable pathways for high -risk endometrial cancer; a TransPORTEC initiative . Mod. Pathol. 2016,28,836 .[ CrossRef]

11. Guest,P.C ; Gottscalk, M.G;Bahn, S . Proteomics : Improving biomarker translation to modern medicine ? Genome Med . 2013, 5,17 .[ CrossRef ]

12. Banach , P;Suchy.w;Derezinski ,P; Matysiak, J; Kokot, Z, J; Nowak- Markwitz, E. Mass spectrometry as a tool for biomarkers searching in gynecological oncology . Biomed Pharmacother . 2017,92,836-842 .. [ CrossRef]

13. Nair, N.; Camacho-Vanegas, O.; Rykunov, D.; Dashkoff, M.; Camacho, S.C.; Schumacher, C.A.; Irish, J.C.; Harkins, T.T.; Freeman, E.; Garcia, I.; et al. Genomic Analysis of Uterine Lavage Fluid Detects Early Endometrial Cancers and Reveals a Prevalent Landscape of Driver Mutations in Women without Histopathologic Evidence of Cancer: A Prospective Cross-Sectional Study. PLoS Med. 2016, 13, e1002206.Martinez-Garcia, E; Lopez-Gil, C;Campoy , I; Vallve , J ; Coll, E ;Cabrera , S; Ramon , Y; Cajal, S; Matias- Guiu,X; Van Ostrum ,J; et al . Advances in endometrial cancerprotein biomarkers for use in the clinic . Expert Rev Proteom 2018, 15,81-99 . . [ CrossRef ]

14. Lorincz, A.T. The promise and the problems of epigenetic biomarkers in cancer. Expert Opin. Med. Diagn. 2011, 5, 375-379Barelli , S;Crettaz, D; Thadikkaran , L ; Rubin , O; Tissot, J . D . Plasma / serum Proteomics : Pre-analytical issues . Expert Rev Proteom 2007, 4, 363-379. .[ CrossRef ]

15. Takenaka, K.; Chen, B.J.; Modesitt, S.C.; Byrne, F.L.; Hoehn, K.L.; Janitz, M. The emerging role of long non-coding RNAs in endometrial cancer. Cancer Genet. 2016, 209, 445-455.

16. Levine, D.A.; Network, C.G.A.R. Integrated genomic characterization of endometrial carcinoma. Nature 2013, 497, 67.

17. Lan, J.; Nunez Galindo, A.; Doecke, J.; Fowler, C.; Martins, R.N.; Rainey-Smith, S.R.; Cominetti, O.; Dayon, L. Systematic Evaluation of the Use of Human Plasma and Serum for Mass-Spectrometry-Based Shotgun Proteomics. J. Proteome Res. 2018, 17, 1426-1435.

18. Shruthi, B.S.; Palani Vinodhkumar, S. Proteomics: A new perspective for cancer. Adv. Biomed. Res. 2016, 5, 67. 
19. Penque, D. Two-dimensional gel electrophoresis and mass spectrometry for biomarker discovery. Proteom. Clin. Appl. 2009, 3, 155-172.

20. Martinez-Garcia, E.; Lopez-Gil, C.; Campoy, I.; Vallve, J.; Coll, E.; Cabrera, S.; Ramon, Y.; Cajal, S.; Matias-Guiu, X.; Van Oostrum, J.; et al. Advances in endometrial cancer protein biomarkers for use in the clinic. Expert Rev. Proteom. 2018, 15, 81-99.

21. Muinelo-Romay, L.; Casas-Arozamena, C.; Abal, M. Liquid biopsy in endometrial cancer: New opportunities for personalized oncology. Int. J. Mol. Sci. 2018, 19, 2311.

22. Barelli, S.; Crettaz, D.; Thadikkaran, L.; Rubin, O.; Tissot, J.D. Plasma/serum proteomics: Pre-analytical issues. Expert Rev. Proteom. 2007, 4, 363-370.

23. Feist, P.; Hummon, A. Proteomic challenges: Sample preparation techniques for microgram-quantity protein analysis from biological samples. Int. J. Mol. Sci. 2015, 16, 3537-3563.

24. Clair, G.; Piehowski, P.D.; Nicola, T.; Kitzmiller, J.A.; Huang, E.L.; Zink, E.M.; Sontag, R.L.; Orton, D.J.; Moore, R.J.; Carson, J.P. Spatially-resolved proteomics: Rapid quantitative analysis of laser capture microdissected alveolar tissue samples. Sci. Rep. 2016, 6, 39223.

25. Martinez-Garcia, E.; Lopez-Gil, C.; Campoy, I.; Vallve, J.; Coll, E.; Cabrera, S.; Ramon, Y.; Cajal, S.; Matias-Guiu, X.; Van Oostrum, J.; et al. Advances in endometrial cancer protein biomarkers for use in the clinic. Expert Rev. Proteom. 2018, 15, 81-99.

26. Li, L.M.; Zhu, Y.X.; Zhong, Y.; Su, T.; Fan, X.M.; Xi, Q.; Li, M.Y.; Fu, J.; Tan, H.; Liu, S. Human epididymis protein 4 in endometrial cancer: A meta-analysis. Clin. Chim. Acta 2018, 482, 215-223.

27. Knific, T.; Osredkar, J.; Smrkolj, Š.; Tonin, I.; Vouk, K.; Blejec, A.; Grazio, S.F.; Rižner, T.L. Novel algorithm including CA-125, HE4 and body mass index in the diagnosis of endometrial cancer. Gynecol. Oncol. 2017, 147, 126-132.

28. Yurkovetsky, Z.; Ta’asan, S.; Skates, S.; Rand, A.; Lomakin, A.; Linkov, F.; Marrangoni, A.; Velikokhatnaya, L.; Winans, M.; Gorelik, E. Development of multimarker panel for early detection of endometrial cancer. High diagnostic power of prolactin. Gynecol. Oncol. 2007, 107, 58-65.

29. Cappello, F;Bellafiore,M;David,S;Anzalone ,R;Zummo ,G. Ten kilodalton heat shock protin (HSP 10) is overexpressed during carcinogenesis of large bowel and uterine exocervix. Cancer Lett. 2003, 196,35-1. [ CrossRef ]

30. Kohler MF, BerchuckA,Davidoff AM, Humphery PA, Dodge RK, Iglehart JD, et al. Overexpression and mutation of p53 in endometrial carcinoma . Cancer Res 1992:52(6):1622-7.

31. Soong R,Knowles S, William KE, Hammond IG, Wysocki SJ, Iacopetta BJ. Overexpression of p53 protein is an independent prognostic indicator in human endometrial carcinoma .Br J Cancer.1996;74:562-7

32. Strang P, Nordstom B, Nilsson S, Bergstrom R, Tribukait B, Mutant p53 protein as a predictor of survival in endometrial carcinoma .Eu J Cancer 1996;32 A :598-602

33. Saffari B, Bernstein L, Hong DC,Sullivan -Halley J, Runnebaum IB, Grill HJ, et al . Association of p53 mutations and a codon 72 single nucleotide polymorphism with lower overall survival and responsiveness to adjuvant radiotherapy in endometroid endometrial carcinomas. Int J Gynecol Cancer . 2005; 15:952-63.

34. Lee EJ, Kim TJ, Kim DS, Choi CH, Lee JW,et al .p53 alteration independently predicts poor outcomes in patients with endometrial cancer : a clinnico pathological study of 11 cases and literature review. Gynecol Oncol .2010;116(3):533-8.

35. Steinbakk A, Skaland I,Gudlaugsson E, Janssen EA, Kjellevold KH, Klos J, et al . The prognostic value of molecular biomarkers in tissue removed from FIGO stage 1 and 2 endometroid type endometrial cancer. Am J Obstet Gynecol .2009; 200(1):78.

36. Risinger JI, Hayes K, Maxwell GL, Carney ME, Dodge RK, Barrett JC, et al PTEN mutation in endometrial cancers is associated with favorable clinical and pathologic characteristics .Clin Cncer Res . 1998;4 (12):3005-10.

37. Mackay HJ, Gallinger S, Tsao MS, Mc Lachlin CM , Tu D, Keiser K, et al . Pognostic value of microsatellite instability (MSI ) nd PTEN expression in women with endometrial cancer : results from studies of the NCIC Clinical Trials Group (NCIC CTG ) . Eur J Cancer. 2010;6(8):1365-73.

38. Maxwell GL, Risinder JI, Alvarez AA, Barett JC, Berchuck A. Favourable survival associated with microstatellite instability and clinical outcome in endometroid endometrial cancer. N Engl J Med . 2000;32 (20:69-77.

39. Basil JB, Goodfellow PJ, Rader JS, Mutch DG, Herzog TJ. Clinical significance of microsatellite instability in endometrial carcinoma . Cancer .2000;89:1758-64.

40. Gryfe R, Kim H, Hsieh ET, Aronson MD, Holowaty EJ, Bull SB , et al . Tumour microsatellite instability and clinical outcome in young patients with colorectal cancer . N Engl J Med. 2000;342 (2) ;69-77.

41. Yeramian A, Moreno -Bueno G, Dolcet X, Catsus L, Abal M, Colas E, et al . Endometrial carcinoma : molecular alterations involved in tumour development and progression. Oncogene. 2013;32 (4):403-13.

42. Fujimoto I, Shimizu Y, Hirai Y, Chen JT , Teshima H, Hasumi K, et al .. Studies on ras oncogene activation in endometrial carcinoma . Gynecol Oncol .1193;8 (2) :196-202.

43. Mizuuchi H, Nassim S, Kudo R, Silverberg SG, Greenhouse S, garette CT . Clinical implications of K-ras mutations in malignant epithelial tumours of the endometrium . Cancer Res . 1992 ;52:2777-81. 
44. Ferrara N, Gerber HP,LeCouter J, The biology of VEGF and its receptors . Nat Med .2003;9: 669-76.

45. Chen CA, Cheng WF, Lee Cn, Wei LH, Chu JS, Hsieh FJ , et al . Cytosol vascular endothelial growth factor in endometrial carcinoma : correlation with disease -free survival . Gynaecol Oncol . 2001; 80 ( 2) : 207-12.

46. Hirai M, Nakagawara A, Oosaki T, Hayashi Y, Hirono M, Yoshihara T. Expression of vascular endothelial growth factors ( VEGF-A / VEGF -1 nad VEGF -C/ VEGF-2) in postmenopausal uterine endometrial cancer . Gynecol Oncol . 2001;80: 181 -8.

47. Talvensaari -Mattila A, Soini Y, Santala m, VEGF and its receptors (flt-1 and KDR/flk-1 0 as prognostic indicators in endometrial carcinoma. Tumour Biol . 2005; 26:81-7.

48. Lundgren C, Auer G,Frankendal B, Nilsson B, Nordstrom B, .Prognostic factors in surgical stage I endometrial carcinoma . Acta Oncol $2004 ; 3:$ 49-56.

49. Hogberg T, Fredstorp- Lidebring M, Alm P, Baldetorp B, Larsson G, Ottosen C, et al . A prospective population -based management program including primary surgery and postoperative risk assessment by means of DNA ploidy and histopathology. Adjuvant radiotherapy is not necessary for the majority of patients with FIGO stage I-II endometrial cancer . Int J Gynecol Cancer ,. 2004 ; 14 (3) 37-50.

50. Susini T, Amunni G, Molino C, Carriero C, Rapi S, Branconi F, et al. Ten year results of a prospective study on the prognostic role of ploidy in endometrial carcinoma : Dna aneuploidy identifies high risk cases among the so called 'low -risk ' patients with well and moderately differentiated tumours . Cancer $2007 ; 109$ (5):882-90 .

51. Colas E, Perez C,Cabera S,Pedrola N, Monge M, Castellvi J, et al . Molecular markers of endometrial carcinoma detected in uterine aspirates . Int J Cancer . 2011; 129(10):235-44

52. Wentzensen N, Bakkum -Gamez JN, Killian JK, Sampson J, Guido R, Glass A, et al . Discovery and validation of methylation markers for endometrial cancer . Int J Cancer 201;12:169.

53. Gallicchio L, Harvey LA, Kjerulff KH, Fear of cancer among women undergoing hysterectomy for benign conditions . Psychosom Med 2005; 67 (3) :20-.

54. Mu, A.K.W.; Lim, B.K.; Hashim, O.H.; Shuib, A.S. Detection of differential levels of proteins in the urine of patients with endometrial cancer: Analysis using two-dimensional gel electrophoresis and 0-glycan binding lectin. Int. J. Mol. Sci. 2012, 13, 9489-9501.

55. Grayson, K.; Gregory, E.; Khan, G.; Guinn, B.A. Urine Biomarkers for the Early Detection of Ovarian Cancer-Are We There Yet? Biomarke. Cancer 2019, 11, $1179299 X 19830977$.

56. Altmae, S.; Esteban, F.J; Stavreus-Evers, A.; Simon, C.; Giudice, L.; Lessey, B.A.; Horcajadas, J.A.; Macklon, N.S.; D'Hooghe, T.; Campoy, C.; et al. Guidelines for the design, analysis and interpretation of 'omics' data: Focus on human endometrium. Hum. Reprod. Update 2014, 20, 12-28.

57. Henry, N.L.; Hayes, D.F. Cancer biomarkers. Mol. Oncol. 2012, 6, 140-146. 